\title{
Novel modified nanocellulose applicable as reinforcement in high-performance nanocomposites
}

\author{
Jelena D. Rusmirovićc ${ }^{a}$, , Jasna Z. Ivanović ${ }^{b}$, Vladimir B. Pavlovićc, ${ }^{c}$, Vesna M. Rakićc ${ }^{c}$, \\ Milica P. Rančić ${ }^{\mathrm{e}}$, Veljko Djokić ${ }^{\mathrm{b}}$, Aleksandar D. Marinković ${ }^{\mathrm{b}}$ \\ a Innovation Center, Faculty of Technology and Metallurgy, University of Belgrade, Karnegijeva 4, 11120 Belgrade, Serbia \\ ${ }^{\mathrm{b}}$ Faculty of Technology and Metallurgy, University of Belgrade, Karnegijeva 4, 11120 Belgrade, Serbia \\ ${ }^{\mathrm{c}}$ Faculty of Agriculture, University of Belgrade, Nemanjina 6, Zemun, 11080 Belgrade, Serbia \\ d Institute of Technical Sciences of the SASA, Knez Mihailova 36, 11000 Belgrade, Serbia \\ e Faculty of Forestry, University of Belgrade, Kneza Višeslava 1, 11030 Belgrade, Serbia
}

\section{A R T I C L E I N F O}

\section{Article history:}

Received 26 September 2016

Received in revised form 16 January 2017

Accepted 22 January 2017

Available online 23 January 2017

\section{Keywords:}

Nanocellulose

Vinyl reactive nanocellulose

Fatty acid modification

Supercritical drying

\begin{abstract}
A B S T R A C T
The influence of modification and vacuum/supercritical $\mathrm{CO}_{2}\left(\mathrm{scCO}_{2}\right)$ drying methods on the surface properties, morphology and thermal stability of cellulose nanocrystals (NC) was presented in this study. Introduction of reactive vinyl groups on NC surface was performed by either direct esterification with oleic acid, linseed or sunflower oil fatty acids; or by amidation of maleic acid/ethylene diamine with methyl ester of fatty acid. Obtained modified NC ( $\mathrm{m}-\mathrm{NC}$ ) were characterized using FTIR and Raman spectroscopy; and by determination of acid, iodine and ester values. Structural analysis of $\mathrm{m}$-NC showed varieties of forms, from spongy to nanostructural non-uniform layered morphology with observable agglomeration, which confirmed morphology dependence on modification/processing methods Thermogravimetry-MS spectrometry showed different thermal stability and degradation pathways of $\mathrm{NC} / \mathrm{m}-\mathrm{NC}$. Incorporation of $1 \mathrm{wt} \%$ of reactive $\mathrm{m}-\mathrm{NC}$ in unsaturated polyester lead to high performance nanocomposites and contributed to increase of stress at break in the range from 76 to $93 \%$.
\end{abstract}

(c) 2017 Elsevier Ltd. All rights reserved.

\section{Introduction}

Environmental regulations and growing demand for high performance products led to the increased interest in renewable and sustainable biomaterials that can be used as reinforcement in polymer composites. Cellulose nanocrystals (NC) are ordered crystalline components that can be extracted from various cellulosic materials. Since the cellulose fibers are composed of amorphous and crystalline regions, rod-shaped nanosized particles remain after the acid hydrolysis of amorphous regions of cellulose fibers. In the case of cellulose nanocrystals obtained by $\mathrm{H}_{2} \mathrm{SO}_{4}$ hydrolysis, the surface of the material becomes negatively charged due to sulfonate ester groups that way causing stability of NC dispersion in aqueous solvents (Dufresne, 2012).

\footnotetext{
* Corresponding author.

E-mail addresses: jrusmirovic@tmf.bg.ac.rs (J.D. Rusmirović), jasnai@tmf.bg.ac.rs (J.Z. Ivanović),

vladimirboskopavlovic@gmail.com (V.B. Pavlović), vesna@ffh.bg.ac.rs (V.M. Rakić), milica.rancic@sfb.bg.ac.rs (M.P. Rančić),vdjokic@tmf.bg.ac.rs (V. Djokić), marinko@tmf.bg.ac.rs (A.D. Marinković).
}

The abundance and biodegradability of these nanoparticles along with high aspect ratio, low coefficient of thermal expansion, high thermal conductivity make them ideal candidates for the processing of polymer nanocomposites (Akur, 2015). Due to its impressive mechanical properties (e.g. the Young's modulus between 115 and $140 \mathrm{GPa}$ ) and a lightweight character (density ca. $1.5 \mathrm{~g} / \mathrm{cm}^{3}$ ), both resulting from hydrogen bonding among NC chains; nanocellulose have a great potential as reinforcement agent in composites, especially in thermosetting ones (Chirayil, Joy, Mathew, Koetz, \& Thomas, 2014; Eichhorn, 2011; Kargarzadeh, Sheltami, Ahmad, Abdullah, \& Dufresne, 2015).

However, there are some serious limitations and drawbacks in the manufacturing of $\mathrm{NC} /$ polymer composites. They arise from their intrinsic physical properties including: high moisture absorption of NC (which degrades the properties of composites based on it), agglomeration of nanoparticles, difficulty in redispersing of agglomerated particles, and incompatibility of NC with hydrophobic polymers (Espert, Vilaplana, \& Karlsson, 2004; Yoo \& Youngblood, 2016). The most optimal manner to avoid drawbacks arising from NC hydrophilicity is hydrophobization of its surfaceby chemical modification. This is enabled by the presence of a large number of hydroxyl groups within nanocellulose 
structure, what presents a unique platform for significant surface modification extending the use of $\mathrm{NC}$ to a wide range of highly sophisticated applications (Habibi, 2014). Pretreatments of the cellulose fibers can modify their surface in a way to avoid water absorption and to increase the surface roughness (Kalia, Kaith, \& Inderjeet, 2009). However, only limited work has been published on NC surface modification by carboxylic fatty acids (Almasi, Ghanbarzadeh, Dehghannya, Entezami, \& Khosrowshahi Asl, 2015; Wei, Stark, Sabo, \& Matuana, 2016; Yoo \& Youngblood, 2016). Besides, there is a necessity to achieve complete residual water removal so to provide compatibility between the cellulose surface and polymer (Peng, Gardner, Han, Cai, \& Tshabalala, 2013). Additionally, it is a challenge to avoid irreversible agglomeration during conventional vacuum drying and re-dispersion of NC during the NC/polymer composite production (Beck, Bouchard, \& Berry, 2012; Peng, Han, \& Gardner, 2012). The NC agglomeration phenomenon, which is a consequence of the formation of hydrogen bonds, is known as hornification (Eyholzer et al., 2010). Based on our best knowledge, the introduction of coupling agents into NC surface, especially with unsaturated residues, causes interaction between the NC and the polymer matrix. It was demonstrated that the methacrylic double bond in silane modified cellulose fibers participated in the free radical polymerization involving styrene and the polyester resin's unsaturations (UPe) (Wei et al., 2016). There were many studies on the influence of vinyl silane modified NC on the mechanical properties of UPe resin, but the effect of the mono/polyunsaturated fatty acid modified NC on UPe based composites was not fully described in the literature. On the other hand, it is also challenging to study the influence of drying method on the NC thermostability and crystallinity. There is some literature evidence about the influence of drying methods (air, freeze, supercritical and spray drying) on the NC thermostability and crystallinity (Peng, Gardner, \& Han, 2012) and supercritical $\mathrm{CO}_{2}$ drying (SCD) was reported as efficient method to produce cellulose nanosized crystals of low specific density (Abdul Khalil et al., 2014; Liebner et al., 2010). Zheng et al. have proven that the SCD treatment increases $\mathrm{NC}$ reactivity, thus enhancing the rate and extent of cellulose hydrolysis (Zheng, Lin, \& Tsao, 1998).

The primary focus of this study is to perform the modification of celullose nanocrystals by unsaturated fatty acids and to elucidate the influence of drying method on the resulting functionalized NCs, produced for the application in unsaturated polyester resin (UPe) based nanocomposites. The aim is to improve the interfacial interaction/reactivity between polymer matrix and NC by surface modification, changing the surface from highly hydrophilic to moderately hydrophobic, as well as introducing fatty acids residues containing reactive vinyl groups as active centres involved in copolymerisation reaction with unsaturated polyester resin. Two types of surface modification of nanocellulose were performed: the first one is the modification with oleic acid (OA), linseed oil or sunflower oil fatty acids (FALO and FASO, respectively); while the second one was done using methyl ester of linseed, sunflower or soybean oil fatty acid attached by maleic acid/ethylene diamine cross-linker to NC surface. The specific objectives of the present study were related to the influence of vacuum and SCD drying on (a) morphological, (b) surface properties, and (c) electrokinetic phenomena of unmodified and $\mathrm{m}-\mathrm{NC}$ nanomaterials.

\section{Experimental}

\subsection{Materials}

\subsubsection{Cellulose nanocrystals (NC) isolation}

Materials which ware used for NC isolation, as well as NC isolation procedure are shown in Supporting information.

\subsection{Isolation of fatty acid (FA) of linseed oil (LO) and sunflower oil (SO)}

Procedure for isolation of fatty acid of linseed and sunflower oil, named FALO and FASO, respectively is presented in Supporting information.

\subsection{Isolation of methyl ester of linseed, sunflower and soybean oil (SOYA) fatty acid}

Isolation of methyl ester of LO was previously described in detail (Rusmirović et al., 2015). According to this procedure, methyl ester of SO and soybean oil (SOYA) fatty acid were isolated in an analogous manner and amounts of reactants, and reaction conditions. The same stands for characterisation of fatty acids mixture (FA) and methyl esters of fatty acids (MEFA): acid value $(A V)$, iodine value $(I V)$, ester content and color are determined and shown in Table S1 (Supporting information).

\subsection{Chemical modification of NC with FAs}

Nanocellulose, obtained by acid hydrolysis method, was modified by esterification with OA and FAs isolated from SO and LO (Fig. S2a). Water dispersion of NC that contains $2 \mathrm{~g}$ dry residue was washed three times with methanol and after that, three times with pyridine in order to change solvent and prepare NC for modification. Obtained residue, after washing with pyridine, was transferred in three-necked round-bottomed flask of $250 \mathrm{ml}$ equipped with nitrogen inlet tube. Afterwards, $100 \mathrm{ml}$ of pyridine, $3.5 \mathrm{~g} p$-toluenesulfonyl chloride and $5 \mathrm{ml}$ of OA or FAs isolated from corresponding oil were added to the flask. The reaction mixture was stirred on the magnetic stirrer and heated for $2 \mathrm{~h}$ at temperature of $50^{\circ} \mathrm{C}$. After completion of the reaction, $100 \mathrm{ml}$ of absolute ethanol was added and the reaction was terminated. Removal of residual solvent and reactants was achieved by repeating centrifugation $(\mathrm{n}=6000 \mathrm{rpm} / \mathrm{min})$ and sonication cycles three times with absolute ethanol.

\subsection{Three step chemical modification of nanocellulose with MEFA via cross-linker}

Modification of NC with MEFA via maleic anhydrideethylenediamine (MA-EDA) cross-linker was presented in Fig. S2b. MA-EDA modification of NC (Supporting information) was done according to the previously described procedure (Taleb et al., 2016) and product was designated as NC-MA-EDA.

After MA-EDA modification, in the third step, NC-MA-EDA was modified with MEFA of LO, SO and SOYA by following procedure: the NC-MA-EDA was placed in $250 \mathrm{ml}$ three-necked flask and dispersed in $50 \mathrm{ml}$ of toluene in an ultrasonic bath; afterwards, $5 \mathrm{~g}$ of MEFA/LO solution in THF was added dropwise. The reaction mixture was stirred and heated for $2 \mathrm{~h}$ on the magnetic stirrer at temperature of $50^{\circ} \mathrm{C}$. After completion of the reaction, the reaction product was washed with absolute ethanol using repeated centrifugation and sonication cycles. The abbreviations of all m-NC samples are presented as follow: NC-bare NC, NC-OA, NC-FALO and NC-FASO-directly linked OA, FALO and FASO, respectively; NCMEFA \LO, NC-MEFA \SO and NC-MEFA \SOYA-methyl ester of LO, SO and SOYA linked via cross-linker MA-EDA (amino terminated moiety at NC surface obtained by amidation of MA residue with EDA).

\subsection{Degree of substitution per anhydroglucose unit}

The degree of substitution value $\left(\mathrm{DS}_{\mathrm{Gr}}\right)$ per anhydroglucose unit was determined by gravimetric measurements and calculated 
using the equations S1 and S2 (Supporting information) (Almasi, Ghanbarzadeh, Dehghannia, Pirsa, \& Zandi, 2015).

\subsection{Supercritical $\mathrm{CO}_{2}$ drying of nanocellulose}

In order to perform better dispersion of NC, dimensional stability and lower density, the SCD drying of unmodified and modified NC was carried out in a semi-batch Autoclave Engineers Screening (Fig. S3; (Supporting information)) designed for small batch research runs using $\mathrm{CO}_{2}$ as the supercritical medium (Stojanović et al., 2013). Prior to SCD, water or solvent of NC dispersions were exchanged with absolute ethanol due to poor affinity of supercritical $\mathrm{CO}_{2}$ $\left(\mathrm{scCO}_{2}\right)$ to water, as well as for providing dimensional stability of crystals (Liebner et al., 2010). Alcogel of $10 \mathrm{ml}$ ethanol NC dispersion ( $40 \mathrm{wt} \% \mathrm{NC}$ in absolute ethanol) were fed to the extractor vessel $(150 \mathrm{ml})$ and exposed to $\mathrm{scCO}_{2}$ at pressure of $20 \mathrm{MPa}$ and $40{ }^{\circ} \mathrm{C}$ (Heath \& Thielemans, 2010) for an hour (static SCD treatment without $\mathrm{scCO}_{2}$ flow) to achieve saturation of the supercritical solvent with absolute ethanol. Subsequently, dynamic SCD treatment (with constant $\mathrm{scCO}_{2}$ flow) was performed at the same pressure and temperature conditions for $2 \mathrm{~h}$. The flow rate of $\mathrm{scCO}_{2}$ during the dynamic SCD was $425 \mathrm{~g} / \mathrm{h}$. At the end of the drying process, the vessel was decompressed slowly at a rate of $1 \mathrm{MPa} / \mathrm{min}$. The influence of $\mathrm{scCO}_{2}$ on $\mathrm{NC}$ at $20 \mathrm{MPa}$ and $40^{\circ} \mathrm{C}$ during static as well as dynamic SCD treatment is shown on Fig. S4 (Supporting information). Obtained NC crystals were further used for morphology and thermal stability investigations.

\subsection{Synthesis of UPe resin}

UPe resins were synthesized from maleic anhydride and products obtained by poly(ethylene terephthalate) (PET) depolymerization with propylene glycol (PG) according to the procedure presented in Supporting information.

\subsection{Preparation of nanocomposites}

Nanocomposites based on UPe (polymeric matrix) and NC was prepared using emulsion blending method. The nanocomposites, UPe/NCR, were obtained by dispersing of $1 \mathrm{wt} \%$ of NC in UPe. The homogenization of NC with UPe was achieved by using a modified laboratory homogenizer and an ultrasonic bath (Bandelin electronic, Berlin, Germany, power $120 \mathrm{~W}$, frequency $35 \mathrm{kHz}$ ). The pure UPe and nanocomposites were cured using $\operatorname{MEKP}(1 \mathrm{wt} \%)$ as the initiator and Co-oct ( $0.5 \mathrm{wt} \%)$ as the accelerator.

\subsection{Characterization methods}

Characterization methodologies are given in Supporting information.

\section{Results and discussion}

\subsection{Yields of NC obtained by acid hydrolysis}

Yield of NC obtained by sulfuric acid hydrolysis is presented in Supporting Information.

\subsection{Degree of substitution per anhydroglucose unit}

The $\mathrm{DS}_{\mathrm{Gr}}$ values of the FAs modified NC are calculated according to the Eq.(S1). The extent of esterification depends on the type of oil used as source of FAs. The $\mathrm{DS}_{\mathrm{Gr}}$ values for NC-OA, NCFALO and NC-FASO are found to be $1.340 \pm 0.002,1.350 \pm 0.002$ and $1.360 \pm 0.002$, respectively.
Table 1

The AV, iodine value and color of m-NC.

\begin{tabular}{llll}
\hline Sample & AV, mg KOH/g & IV & Color \\
\hline VC dried NC & 28.0 & $<3$ & White \\
SCD dried NC & 15.0 & $<3$ & White \\
FA modified NC & AV, $\mathrm{mg} \mathrm{KOH} / \mathrm{g}^{\mathrm{a}}$ & $\mathrm{IV}$ & Color \\
& 18.0 & 26.2 & White \\
NC-OA & 15.0 & 29.7 & White \\
NC-FALO & 14.0 & 27.8 & White \\
NC-FASO & & & \\
MEFA modified NC & $\mathrm{AV}, \mathrm{mg} \mathrm{KOH} / \mathrm{g}$ & $\mathrm{IV}$ & Color \\
& $<3$ & 15.1 & Light yellow \\
NC-MEFA/LO & $<3$ & 9.8 & Light yellow \\
NC-MEFA/SO & $<3$ & 14.3 & Light yellow \\
NC-MEFA/SOYA & (R) &
\end{tabular}

From the results for $\mathrm{DS}_{\mathrm{Gr}}$ of the FAs modified NC, it can be seen that the highest value is obtained in case of NC-FASO, while lower values are obtained in the case of NC-OA and NC-FALO due to different percentages of unsaturated $F A s$. $\mathrm{DS}_{\mathrm{Gr}}$ decreased when the fatty acid chain length and the number of double bonds in the fatty acid chain were increased (Uschanov, Johansson, Maunu, \& Laine, 2011 ). FASO contains $\approx 59 \%$ polyunsaturated linoleic acid with two double bonds in structure, while FALO contains $\approx 71.5 \%$ polyunsaturated FAs with three and two double bonds ( $\alpha$-linolenic and linoleic acid).

\subsection{Acid and iodine values}

The AV and IV of VC and SCD dried NC, as well as m-NC are given in Table 1. Differences in IV for unmodified NC and m-NC arise from different surface functional groups indicating successfulness of nanocellulose modification with FAs, as well as with MEFAs. Increased IV for m-NC are due to unsaturated FAs introduced on NC surface.

The two approaches allowed introduction of FA residues without provoking damage of the basic structure. The first one provides direct attachment. The second method was performed by three step modification of $\mathrm{NC}\left(\mathrm{AV}=28 \mathrm{mg} \mathrm{g}^{-1}\right)$ with MA to NC-MA, on that way $\sim 1.50 \mathrm{mmolg}^{-1}$ of carboxylic group was introduced $\left(\mathrm{AV}=150 \mathrm{mg} \mathrm{g}^{-1}\right)$. The lower efficiency of NC-MA modification, i.e. amidation, with EDA produced $0.92 \mathrm{mmol} \mathrm{g}^{-1}$ of amino terminal groups ( $\sim 61 \%$ conversion) in NC-MA-EDA. By subsequent modification, (i.e. introduction of fatty acids by amidation of terminal amino group with FAs) a number of vinyl containing moieties were introduced (Table 1). From the determination of IV value (Table 1) of $\mathrm{m}-\mathrm{NC}$, it was estimated that degree of modification for NC-FALO, NC-FASO and NC-OA was $18.9 \%, 19.5 \%$ and $20.4 \%$, respectively. In the case of MEFA NC modification, it was estimated that degree of introduced FA residues was $8.8 \%, 10.1 \%, 10.9 \%$ for NC-MEFA/SO, NC-MEFA/LO, NC-MEFA/SOYA, respectively.

\subsection{FTIR analysis of nanocellulose}

Analysis of FTIR spectra (Fig. 1a and b) of the isolated NC, as well as NC modified with FA and MEFA via cross-linker, gave information about the functional groups and the extent of interaction between the surface functional groups of NC and reactive groups present on the modifiers chains. No observable differences were noticed in the FTIR spectra, what could be significant for the consideration of the influence of drying method (VC and SCD) on the properties of obtained materials.

In FTIR spectra of both unmodified and m-NC, a broad band at around $3300-3500 \mathrm{~cm}^{-1}$ can be observed which originates from hydroxyl group $(\mathrm{OH})$ stretching vibrations. The decrease in the intensity of band assigned to stretching $\mathrm{OH}$ vibrations can be 

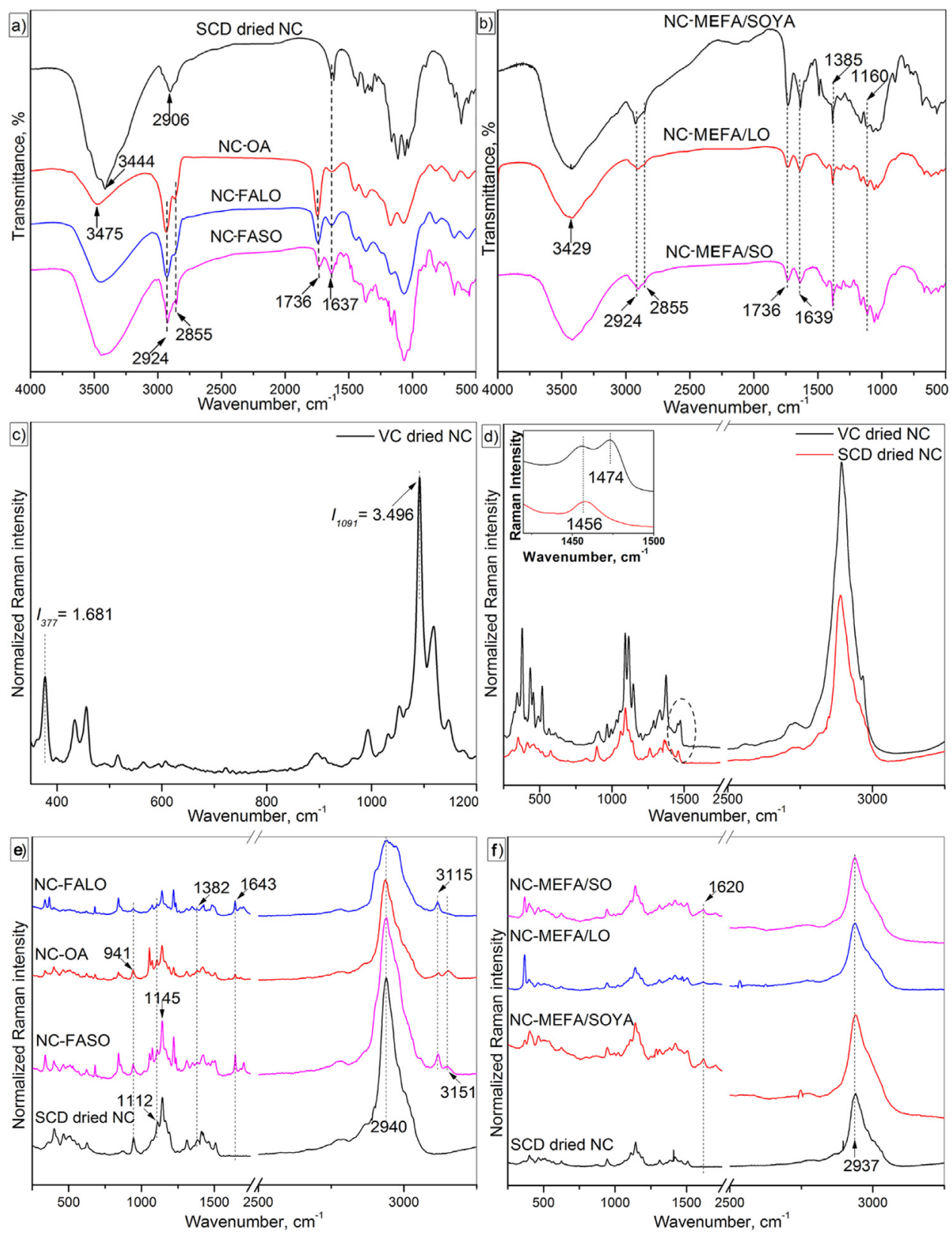

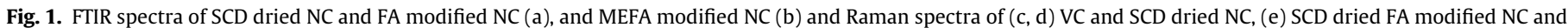
(f) MEFA modified NC via cross-linker.

noticed for modified NC if compared with the one found for unmodified one. The high intensity $\mathrm{OH}$ stretching vibration is due to hydrogen bonding of exposed hydroxyl group in starting NC. Otherwise, decreased intensity of this group in modified material is due to introduction of fatty acid residues contributing to shielding effect of surface groups (Almasi, Ghanbarzadeh, Dehghannya et al., 2015). The absorption peak at $1736 \mathrm{~cm}^{-1}$ derived from the ester carbonyl groups confirms successful modification with OA and FAs isolated from LO and SO (Fig. 1a), as well as from the carbonyl group of MA moiety (Fig. 1b). The band that appears in the region $2855-2924 \mathrm{~cm}^{-1}$ corresponds to C-H stretching of NC skeleton and FA chains (Joly, Granet, Branland, Verneuil, \& Krausz, 2005). Absorption peak at $1637 \mathrm{~cm}^{-1}$ originates from symmetric deformational vibrations of native NC and water molecules absorbed at the surface, though FTIR spectra were recorded for samples dried at $\mathrm{scCO}_{2}$ conditions. The intensity of those peaks decreased with substitution of hydroxyl groups with non-polar acid residues which cause an increase in surface hydrophobicity (Hu, Chen, Xu, \& Wang, 2011). The bands between $750 \mathrm{~cm}^{-1}$ and $1000 \mathrm{~cm}^{-1}$, as well as the other bands around $1385 \mathrm{~cm}^{-1}$ and $1160 \mathrm{~cm}^{-1}$, show the presence of sulfonate groups on the surface of nanocellulose samples (Socrates, 2004). The bands in this area are overlapped with $\delta(\mathrm{C}-\mathrm{H})$ and $\gamma(C-H)$ vibrations from the olefin $(C=C)$ groups present in the FA and MA moieties. Absorption peak at $1639 \mathrm{~cm}^{-1}$ originates from the $\delta\left(\mathrm{NH}_{2}\right)$ stretching vibration (Fig. $\left.1 \mathrm{~b}\right)$ is overlapped with symmetric deformational vibrations peak of native NC. By comparison of FTIR spectra of unmodified and $\mathrm{m}-\mathrm{NC}$, the strengthening of the ester carbonyl group peak was observed which is missing in the FTIR spectrum of bare NC.

\subsection{Raman spectroscopy}

The Raman spectroscopy was applied to study the influence of the NC drying method and properties of the surface modifiers on 
degree of crystallinity of produced NC. Raman crystallinity $\left(X_{\text {Raman }}\right)$ of VC dried NC was determined by calculating the peak height ratio $\left(I_{377} / I_{1091}\right)$ using Eq. S4 (Agarwal, Reiner, Filpponen, Isogai, \& Argyropoulos, 2010). Raman spectra were normalized in relation to $897 \mathrm{~cm}^{-1}$ band whose height was minimally impacted by change in crystallinity (Agarwal et al., 2010). The intensity of Raman (\% transmittance) at $377 \mathrm{~cm}^{-1}$ and at $1091 \mathrm{~cm}^{-1}$ was found to be 1.681 and 3.496 , respectively. The $X_{\text {Raman }}$ was found to be $69.6 \%$. Raman spectra of VC and SCD dried unmodified NC, and SCD dried FA and MEFA modified NC are shown in Fig. 1c-f.

Raman spectroscopy gave the information about different vibrational behavior between crystalline and amorphous NC domain (Schenzel, Fischer, \& Brendler, 2005). The Raman signals, observed at $1456 \mathrm{~cm}^{-1}$ and $1474 \mathrm{~cm}^{-1}$ in the spectrum of VC dried NC, originate from methylene bending stereo chemically nonequivalent $\mathrm{CH}_{2} \mathrm{OH}$ groups in the NC skeleton. Comparing Raman spectra of samples before and after SCD drying indicated that two signals at $1456 \mathrm{~cm}^{-1}$ and $1474 \mathrm{~cm}^{-1}$ merge into one single signal at $1456 \mathrm{~cm}^{-1}$ due to the transition from crystalline to amorphous form (Fig. 1d). The similar result was found for FAs modified NC and for samples modified with MEFA via cross-linker (Figs. 1 e) and 3 f). Peng, Gardner, Han, Kiziltas et al., (2013) have studied the influence of drying method on the material properties of nanocellulose and showed that SCD drying produced nanofibrilar NC of minimal thermal stability and the lowest crystallinity index.

Raman spectra of $\mathrm{NC}$ can be divided into region below $1750 \mathrm{~cm}^{-1}$ and region above $2700 \mathrm{~cm}^{-1}$. Conformation of the NC skeleton can be observed at region below $1750 \mathrm{~cm}^{-1}$ (especially below $700 \mathrm{~cm}^{-1}$ ), while hydrogen bonding of $\mathrm{OH}$ group can be noticed in the second region at about $3000 \mathrm{~cm}^{-1}$ (Schenzel et al., 2005). Raman spectra of all NC samples showed weak band in the range from 941 to $1112 \mathrm{~cm}^{-1}$ originating from $\mathrm{H}-\mathrm{C}-\mathrm{C}$ and $\mathrm{H}-\mathrm{C}-\mathrm{O}$ bending at $\mathrm{C} 6$ atom. The strong band observed at $1145 \mathrm{~cm}^{-1}$ and $1420 \mathrm{~cm}^{-1}$ originates from $\mathrm{C}-\mathrm{C}, \mathrm{C}-\mathrm{O}$ and $\mathrm{C}-\mathrm{O}-\mathrm{C}$ stretching vibration of unhydroglucopyranose skeleton unit (Wiley and Atalla, 1987), and these bands were overlapped with the symmetric and asymmetric $C=C$ stretching vibrations (Lee, Ling, \& Chan, 2008). The band observed at $1380 \mathrm{~cm}^{-1}$ originates from various cellulose backbone deformation vibrations: $\delta\left(\mathrm{CH}_{2}\right), \delta(\mathrm{H}-\mathrm{C}-\mathrm{C}), \delta(\mathrm{H}-\mathrm{C}-\mathrm{O})$ and $\delta(C-O-H)$ (Zhang, Feldner, \& Fischer, 2011). The stretching vibrations of $\mathrm{C}=\mathrm{O}$ bond in ester group, observed in Raman spectra of FA modified NC (Fig. 1e), appear at $1643 \mathrm{~cm}^{-1}$. This band is shifted to the lower values $\left(1620 \mathrm{~cm}^{-1}\right)$ in the Raman spectra of MEFA modified NC via cross-linker (Fig. 1f). The bands in the region over then $3000 \mathrm{~cm}^{-1}$ observed in Raman spectra of FA m-NC (Fig. 1f), originates from $\delta(\mathrm{C}-\mathrm{O}-\mathrm{H})$ stretching vibrations (Szymańska-Chargot et al., 2011).

\subsection{TGA-MS analysis}

Thermal analysis of unmodified NC (VC and SCD dried) and NC modified with FAs and MEFAs via cross-linker showed that introduced thermally unstable surface modifiers produced volatiles fragments released during the dehydration, hydrolysis, oxidation, decarboxylation and transglycosylation reactions (Peng, Gardner et al., 2012). Obtained TGA curves are shown in Fig. 2a and b. Thermal degradation of unmodified NC, SCD and VC dried, and all $\mathrm{m}$-NC samples takes place in a three-step reactions: process which takes place at decomposition temperature $\leq 200^{\circ} \mathrm{C}$ (i), the other observed between 200 and $300^{\circ} \mathrm{C}$ (ii), and the last one found at temperatures higher than $300^{\circ} \mathrm{C}$ (iii). Similar behaviour was observed for SCD dried NC with exception of transition temperature between the first and the second stage, found at $245^{\circ} \mathrm{C}$, and significantly steeper/faster degradation process in the second stage. Thermograms of m-NC showed rapid weight loss at decomposition temperature from 237 to $300^{\circ} \mathrm{C}$ and from 155 to $224^{\circ} \mathrm{C}$ for unmod- ified and MEFA modified NC, and FAs modified NC, respectively. Also, DTG indicated higher uniformity of NC, as well as less difficult evaporation of water in SCD dried NC compared to VC dried ones (Peng, Gardner, Han, Kiziltas et al., 2013). It means that postprocessing of obtained material highly affected the agglomeration of NC: VC drying caused stepwise dehydration accompanied with random agglomeration leading to broad distribution of the radius of NC agglomerates; what gives rise to multiple peaks in the DTG curves. Similar thermal stability was found for air-dried NC (Peng, Gardner, Han, Kiziltas et al., 2013).

All m-NC samples showed low weight loss from initial temperature $\left(25^{\circ} \mathrm{C}\right.$ ) to $155^{\circ} \mathrm{C}$ and $237^{\circ} \mathrm{C}$ (Fig. 2b), originating from the moisture content or residual reactants, taking place in the temperature range of the first decomposition region (Region I - dehydration drying/reactant residue removal). The transition temperature was shifted to the higher temperature for the $\mathrm{scCO}_{2}$ dried MEFA m-NC. Also, the weight loss is higher for the VC dried (11.5\%) than for $\mathrm{scCO}_{2}$ dried NC (7.0\%) (Fig. 2a), NC-MEFA/LO (7.7\%), NC-OA, NC-FALO, and NC-FASO $(\approx 3.3 \%)$, and the highest weight loss is observed for NCMEFA/SOYA (13.3\%). The lower extent of dehydration, observed for NC modified with various long FA chains, could be due to lower availability of surface $\mathrm{OH}$ groups and thermal reactivity of fatty acid residues which form a protective layer.

The crystal structure decomposition of the unmodified NC (Region II; Fig. 2a) takes place via two competitive reactions: dehydration to anhydrocellulose and depolymerization to levoglucosan (Peng, Gardner et al., 2012). Since it starts from $230^{\circ} \mathrm{C}$, the peaks of the unmodified and MEFA modified NC occur at $237^{\circ} \mathrm{C}$. The crystal structure decomposition of the FA modified NC are noticed at lower temperatures, $155^{\circ} \mathrm{C}$.

The onset of degradation was shifted to lower temperatures with increasing carbon chain length of organic acids attached to the surface of NC (Fig. 2b). Menezesa et al. demonstrated that with the increase of the acid carbon chain length, the temperature at which the weight loss of NC nanofibres showed maximum rate decreases. This was presumably due to the reduced number of surface hydroxyl groups involved in the esterification reaction, and on that way effectiveness of the potential of hydrogen bonds between NC nanostructures have been decreased (Junior de Menezes, Siqueira, Curvelo, \& Dufresne, 2009). This resulted in the reduction of inter-particular hydrogen bonds formation between nanostructures that further reduces the thermal stability compared to neat NC. The opposite was found for MEFA modified NC. A shape of the curve of weight loss of $\mathrm{m}$-NC originates from the differences in thermal stability/reactivity of the structure of attached FA/MEFA moieties (Fig. 2). In the range $200-300^{\circ} \mathrm{C}$, the TGA profile is fairly similar for MEFA m-NC indicating that weight loss is of low dependence on the structure of fatty acid residues. However, in the range $300-500^{\circ} \mathrm{C}$, the appropriate influences of structural differences could be observed, mostly arising from the chain length/structure of fatty acid residues. Differences in degradation profile/reactivity of unsaturated aliphatic is mainly due to easily abstractable hydrogens present in trienoate structure, what results in formation of highly reactive allyl type radicals capable for reactivity transfer and cross-linking reaction. Synergetic contribution of these reactions and thermal degradation produce condensed surface structures which thermally decompose at higher temperatures.

The differential scanning calorimetry (DSC) was performed in this study; heating runs were performed in the temperature range $25-500{ }^{\circ} \mathrm{C}$ with a heating rate of $5^{\circ} \mathrm{C} \mathrm{min}^{-1}$. The results of DSC analysis of the unmodified NC, VC and SCD dried, and m-NC are shown in Table 2.

Similar values of endothermic peak position $\left(\mathrm{T}_{1}\right)$ were observed in the temperature region $\leq 104.5^{\circ} \mathrm{C}$ (Region I of NC decomposition) for all NC samples (Table 2). In this region, the observed endothermic effect originates from dehydration (drying)/reactant 

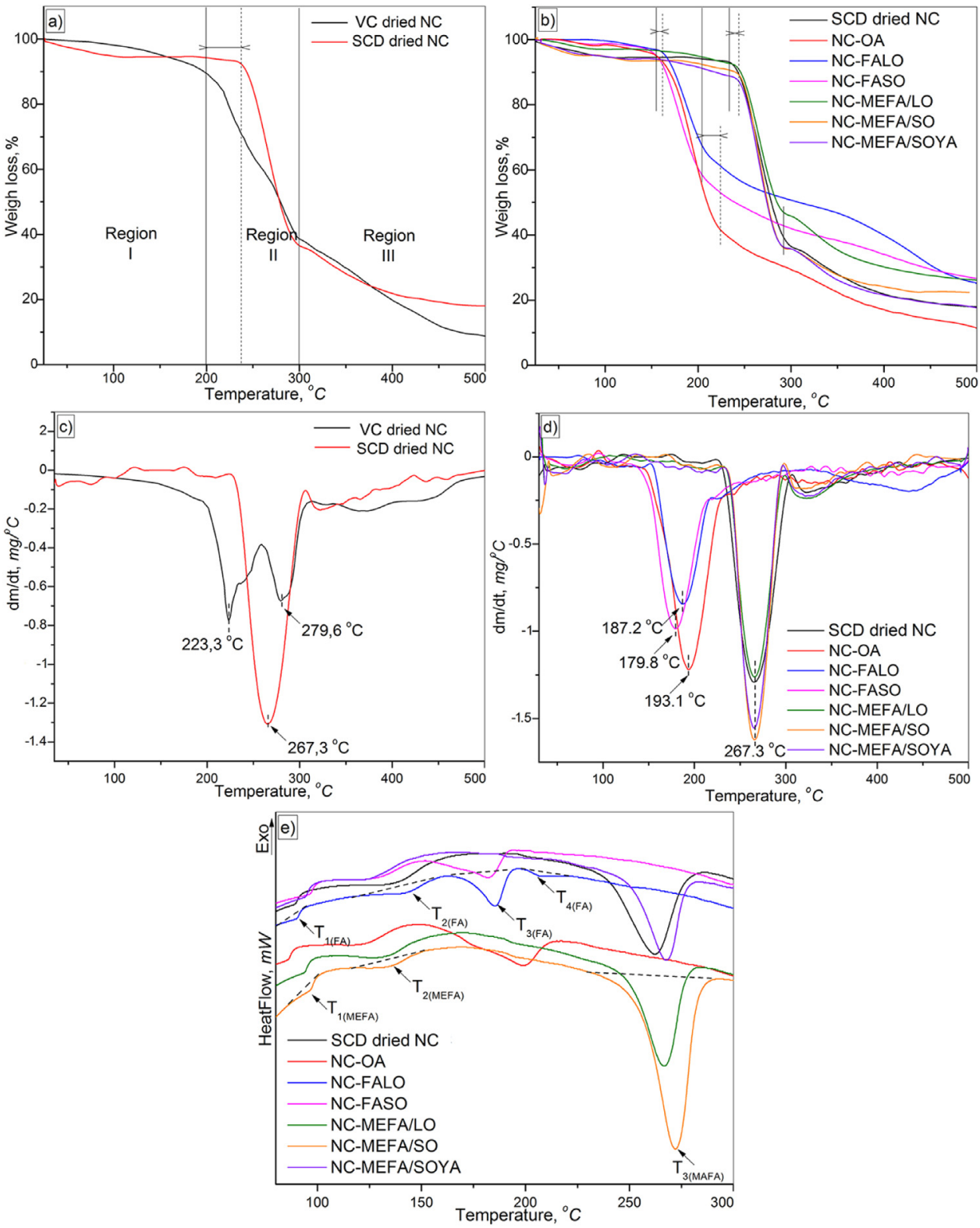

Fig. 2. TGA curves of VC and SCD dried unmodified NC and FAs and MEFA modified NC (a) and (b), corresponding DTG curves (c) and (d), and DSC thermograms of all samples (e).

Table 2

The DSC endothermic heat of the SCD dried unmodified and m-NC.

\begin{tabular}{|c|c|c|c|c|c|c|c|c|}
\hline Sample & $\mathrm{T}_{1}\left[{ }^{\circ} \mathrm{C}\right]$ & $\Delta H[\mathrm{~J} / \mathrm{g}]$ & $\mathrm{T}_{2}\left[{ }^{\circ} \mathrm{C}\right]$ & $\Delta H[\mathrm{~J} / \mathrm{g}]$ & $\mathrm{T}_{3}\left[{ }^{\circ} \mathrm{C}\right]$ & $\Delta \mathrm{H}[\mathrm{J} / \mathrm{g}]$ & $\mathrm{T}_{4}\left[{ }^{\circ} \mathrm{C}\right]$ & $\Delta H[\mathrm{~J} / \mathrm{g}]$ \\
\hline SCD dried NC & 89.2 & 9.4 & 135.5 & 58.4 & 261.6 & 417.5 & - & - \\
\hline
\end{tabular}

FA modified NC

\begin{tabular}{|c|c|c|c|c|c|c|c|c|}
\hline & $\mathrm{T}_{1 \text { (FA) }}\left[{ }^{\circ} \mathrm{C}\right]$ & $\Delta H[\mathrm{~J} / \mathrm{g}]$ & $\mathrm{T}_{2(\mathrm{FA})}\left[{ }^{\circ} \mathrm{C}\right]$ & $\Delta H[\mathrm{~J} / \mathrm{g}]$ & $\mathrm{T}_{3(\mathrm{FA})}\left[{ }^{\circ} \mathrm{C}\right]$ & $\Delta H[\mathrm{~J} / \mathrm{g}]$ & $\mathrm{T}_{4(\mathrm{FA})}\left[{ }^{\circ} \mathrm{C}\right]$ & $\Delta H[\mathrm{~J} / \mathrm{g}]$ \\
\hline NC-OA & 92.6 & 18.9 & 145.1 & 92.2 & 195.6 & 275.4 & 229.3 & 7.6 \\
\hline NC-FALO & 89.7 & 12.4 & 161.9 & 22.0 & 196.4 & 73.9 & 207.5 & 8.3 \\
\hline NC-FASO & 95.9 & 11.5 & 128.1 & 29.7 & 182.4 & 102.2 & - & - \\
\hline
\end{tabular}

MEFA modified NC

\begin{tabular}{|c|c|c|c|c|c|c|c|c|}
\hline & $\mathrm{T}_{1 \text { (MEFA) }}\left[{ }^{\circ} \mathrm{C}\right]$ & $\Delta H[\mathrm{~J} / \mathrm{g}]$ & $\mathrm{T}_{2 \text { (MEFA) }}\left[{ }^{\circ} \mathrm{C}\right]$ & $\Delta H[\mathrm{~J} / \mathrm{g}]$ & $\mathrm{T}_{3 \text { (MEFA) }}\left[{ }^{\circ} \mathrm{C}\right]$ & $\Delta H[\mathrm{~J} / \mathrm{g}]$ & $\mathrm{T}_{4(\mathrm{MEFA})}\left[{ }^{\circ} \mathrm{C}\right]$ & $\Delta H[\mathrm{~J} / \mathrm{g}]$ \\
\hline NC-MEFA/LO & 93.4 & 4.0 & 131.0 & 29.8 & 266.3 & 268.4 & - & - \\
\hline NC-MEFA/SO & 96.2 & 1.2 & 133.6 & 7.4 & 271.9 & 236.1 & - & - \\
\hline NC-MEFA/SOYA & 93.8 & 14.3 & 124.8 & 29.4 & 267.6 & 232.2 & - & - \\
\hline
\end{tabular}


residue removal, as well as conformational rearrangements of flexible structure of FA residues. Thermal softening of surface functionalities contributes to material shrinkage and tight interconnection/higher level of interpenetration of surface modifiers. Hirata and Nishimoto (Hirata \& Nishimoto, 1991) investigated thermal behaviour of untreated cellulose and that one treated with flame-retardants. They revealed that the broad endothermic peak found in low-temperature region (between 93 and $179^{\circ} \mathrm{C}$, denoted as $\mathrm{T}_{2}$ ), occurs due to the random chain scission. In this temperature interval, the glycosidic bonds cleavage causes the polymerization degree reduction without accompanying substantial production of levoglucosan. The degradation of levoglucosan occurs at higher temperatures in the range of $150-280^{\circ} \mathrm{C}$ (Region II) as a result of crystal structure decomposition, and it is responsible for the greatest weight loss. The endothermic effect of crystal structure decomposition is designated as $\mathrm{T}_{3}$ peak on DSC curves (Fig. 2e). Obtained results are in accordance with TGA analysis and indicate that crystal structure decomposition of the FA modified NC occurred at lower temperatures $\left(T_{3}\right)$ compared to the unmodified and MEFA modified one.

Surface NC modification causes changes in the endothermic heat (Table 2) with obvious differences between FA and MEFA modified NC. The influences of surface modifiers on thermal behaviour of FA modified NC could be noticed in both Region II and III, while observable change in TGA curves for MEFA modified NC was noticed for Region III (Fig. 2b). The highest value of DSC endothermic heat $(\Delta H)$ was observed for $\mathrm{NC}-\mathrm{OA}$ at $\mathrm{T}_{2(\mathrm{FA})}=145.1^{\circ} \mathrm{C}$ (chain scission region) which indicates that introduction of $\mathrm{OA}$ with one unsaturated bond increased thermal stability, while the conjugated unsaturated bonds, in FALO, FASO, MEFA/LO and MEFA/SOYA moieties contribute to the opposite effect. The presence of MEFA on $\mathrm{m}$-NC surface contributes to higher availability/reactivity of crosslinking (vinyl) groups (Table 2), and thus exhibit specific influence on $\Delta H$ values. The most of heat in Region II was consumed in a cross-linking reaction (because of that no observable change was notice in a TGA curves of Region II), while in Region III weight loss curves reflect the effect of non-homogeneous nature of condensed material on TGA profiles.

Along with controlled temperature increase, the MS was set to collect: molecular ions, fragments which could result from the decomposition of analyzed NC materials. Most of detected ions in MS spectra are various oxygen-containing fragments: probably acetate ion $(m / z=59)$ (Jecklin, Gamez, \& Zenobi, 2009); water $(m / z=18)$ (Tosh, 2011) and $\mathrm{CO}_{2}(m / z=44)$. The obtained MS signals of acetate ions, water and $\mathrm{CO}_{2}$ are shown of Fig. 3 .

As it can be seen from Fig. 3a and b, the MS signal of acetate ion $(m / z=59)$ was monitored along the temperature-programmed heating of all the NC samples, at lower (Region I; Fig. 2) as well as at higher temperature (NC skeleton decomposition-Region II; Fig. 2). This indicated contribution of two processes: defragmentation/decomposition of celobioze unit or desorption of tightly bonded/ester bonded acetic acid from ester group in FA.

From Fig. $3 c$ and $d$, it can be seen that the peak $m / z=18$ (main fragmentation of water molecule) corresponds to the NC crystal structure decomposition signal (occurs at Region II). It is evident that for the FAs modified NC it is shifted to the lower temperature $\left(187\right.$ and $198^{\circ} \mathrm{C}$ ). During decomposition of native and MEFA modified NC signal $m / z=18$ occurres at about $270^{\circ} \mathrm{C}$. This peak was missing in the NC-FASO sample. Water was formed during thermal decomposition of the cellulose, and explained by dehydration reaction of large number of $\mathrm{OH}$ groups present in carbohydrate structure (Sebestyén, Jakab, May, Sipos, \& Réczey, 2013).

In Fig. 3e and fragmentation pathways of unmodified and FAs modified $\mathrm{scCO}_{2}$ dried NC are shown. Production of $\mathrm{CO}_{2}$ fragment $(\mathrm{m} / \mathrm{z}=44)$ was attributed to the presence of surface oxygen functional groups and the carboxylic acid functions (Postole, Bennici,
\& Auroux, 2009). The MS signals of $\mathrm{CO}_{2}$, observed below $300^{\circ} \mathrm{C}$ for native, $\mathrm{OA}$ and $\mathrm{FALO}$, originate from oxygen functional groups present on NC skeleton, and follow the crystal structure decomposition signal (Region II). Additionally, the $\mathrm{CO}_{2} \mathrm{MS}$ signals, observed at higher temperature than $360^{\circ} \mathrm{C}$, originate from carboxylic acid groups. This MS signal was missing in the NC-FASO sample which indicates the higher thermal stability compared to native, OA and FALO modified NC.

\subsection{Morphology analysis}

Atomic force microscopy (AFM) of the initial NC is performed; the results of AFM analysis are presented in Supporting information (Fig. S5) while TEM micrograph is shown on Fig. 4i. It can be seen from the results obtained by AFM that the lengths of rod-like shape NC crystals are in the range from 200 to $400 \mathrm{~nm}$ (average value: $260 \pm 130 \mathrm{~nm}$ ), while their diameters are in the range from 70 to $155 \mathrm{~nm}$ (average values: $88 \pm 45 \mathrm{~nm}$ ). The TEM micrograph shows mixture of spherical and rod-like shape NC which have an diameter in the range of $\approx 7.0-18.5 \mathrm{~nm}$, and from aggregates of different diameter size, mostly from $\approx 40.0-60.0 \mathrm{~nm}$ and rarely high dimensions aggregates $(\approx 186 \mathrm{~nm})$, similarly as already published (Ibrahim, Hussin, \& Al-obaidi, 2015).

The morphologies of native vacuum and SCD dried NC, as well as NC modified with OA and FA of LO and SO oils, and MEFA of SOYA, LO and SO via cross-linker were characterized by SEM microscopy, representative SEM images are shown in Fig. 4a-h.

The VC dried NC particles has ellipsoidal structure (Fig. 4a) and non-porous structure composed from agglomerated NC units with dimension of approximately 330-570 nm. During SCD drying, spongy-like aerogels with no observable shrinkage are obtained due to the lack of surface tension of $\mathrm{scCO}_{2}$. Such properties of $\mathrm{scCO}_{2}$ prevent the structure from collapsing. From Fig. $4 \mathrm{~b}$, it can be seen that the unmodified NC has the most pronounced spongylike morphology with NC length of $\approx 93-200 \mathrm{~nm}$ and diameter of $\approx 50 \mathrm{~nm}$ compared with the modified ones. NC modified via FAs retained porous spongy-like structure with random cluster creation of agglomerated particles produced during the modification reaction (Fig. 4c-e). The MEFA modified NC samples (Fig. $4 \mathrm{f}-\mathrm{h}$ ) have lost spongy-like morphology in a great extent and the particles are packed into a non-uniform layered structure with a number of created clusters, that is more pronounced than in FAs modified samples. Kulomaa et al. (Kulomaa et al., 2015) have showed that FAs modification of NC (isostearic and oleic acid) has significant effects on its original morphology due to dissolution and casting caused by introduction of unsaturation and reactants branching. Taking into account all NC samples modified with fatty acids, NC-FASO have showed the lowest porous structure and the highest loss of fibrillar morphology. On the other side, there is no significant difference among morphology of MEFA modified NC samples.

\subsection{Electrokinetic phenomena}

In order to understand the interaction between $\mathrm{NC}$ and modifying agent, the changes in the NC electrokinetic phenomena were determined through the determination of electrokinetic (zeta- $\zeta$ ) potential; which evaluation is based on the Smoluchowski equation (Bellmann et al., 2005). The results obtained using suspensions of unmodified and $\mathrm{m}-\mathrm{NC}$ in the deionised water are shown in Table 3.

Results presented in Table 3 show that the SCD dried NC had the greatest negative value of $\zeta$ which indicated rather developed surface providing that net surface charge, present in the region bounded by the slipping plane, is effectively bounded by the electrostatic interaction with surface functionalities. The VC dried NC had the lowest negative value of $\zeta$ conditioned by the presence of completely dissociable (sulfate) acidic surface groups 

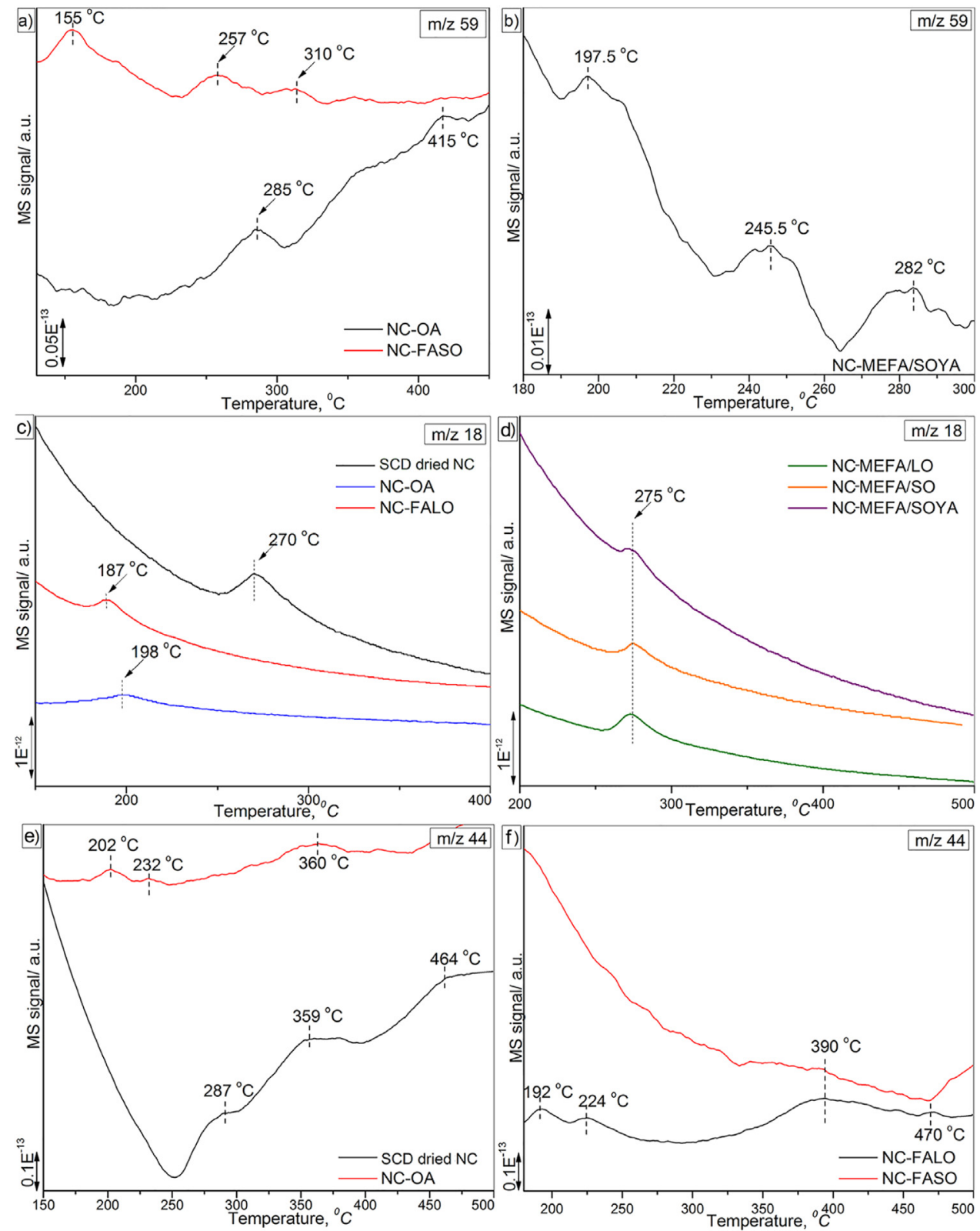

Fig. 3. MS signals $m / z=59$ ( $\mathrm{a}$ and $\mathrm{b}$ ), $m / z=18$ ( $\mathrm{a}$ and $\mathrm{b}$ ) and $m / z=44$ ( $\mathrm{a}$ and $\mathrm{b}$ ) recorded during the heating of the unmodified NC and FAs modified and MEFA modified NC;

Table 3

The mass percent composition, $\mathrm{pH}$ value ${ }^{\mathrm{a}}$, zeta potential and particle size of unmodified and $\mathrm{m}-\mathrm{NC}$.

\begin{tabular}{lllll}
\hline Sample & $\omega, \%$ & $\mathrm{pH}$ & $\zeta, \mathrm{mV}$ & Particle size, $\mathrm{nm}^{\mathrm{a}}$ \\
\hline VC dried NC & 0.10 & 5.50 & $-37.1 \pm 1.0$ & $" 8000$ \\
SCD dried NC & 0.10 & 6.23 & $-71.0 \pm 0.3$ & 400 \\
NC-FALO & 0.01 & 6.10 & $-49.8 \pm 0.3$ & 702 \\
NC-FASO & 0.01 & 6.10 & $-55.8 \pm 1.4$ & 293 \\
NC-MEFA/SOYA & 0.01 & 5.95 & $-43.6 \pm 0.2$ & 280 \\
\hline
\end{tabular}

a All aqueous suspensions appeared to be poly-dispersed system (containing the particles of different diameters). Presented numbers give diameter of most abundant particles.

(Bellmann et al., 2005). Slightly lower $\zeta$ values were observed at chemically modified $\mathrm{NC}$ : $-55.8 \mathrm{mV},-49.8 \mathrm{mV}$ and $-43.6 \mathrm{mV}$ for NC-FASO, NC-FALO and NC-MEFA/SOYA nanomaterials, respectively. Introduction of FA and MEFA on the NC surface decreased the hydrophilicity which was reflected in the $\zeta$ values change, but the greatest influence had SCD pretreatment. The higher $\zeta$ values found for $\mathrm{m}-\mathrm{NC}$ indicate that introduced modifiers do not contain dissociable group capable to contribute to significant change of surface charge. Direct introduction of FA occupies some hydroxyl groups at NC surface by changing surface functionalities to more hydrophobic which exert repelling effect to counter anions present in surrounding double layer. Therefore, the adsorption of electrolyte ions on the $\mathrm{m}-\mathrm{NC}$ surface is mainly governed by present surface functionalities. Otherwise, the modification of NC with MA-EDA and subsequently with SOYA (Table 3 ) brings to higher $\zeta$ which was due to presence of amphiphilic groups containing hydrophilic/hydrophobic moieties (proton-donating/proton-accepting sites) which affect higher extent of surface wetting and thus higher interaction forces between present anions and the m-NC surface.

By determination of the particle size, it was confirmed that applied SCD method preserved nano-sized dimensions of NC (Abdul Khalil et al., 2014; Liebner et al., 2010). The application of the VC drying method resulted in the NC dimensions greater than $8 \mu \mathrm{m}$. SCD treatment of NC contributes to the prevention of agglomera- 


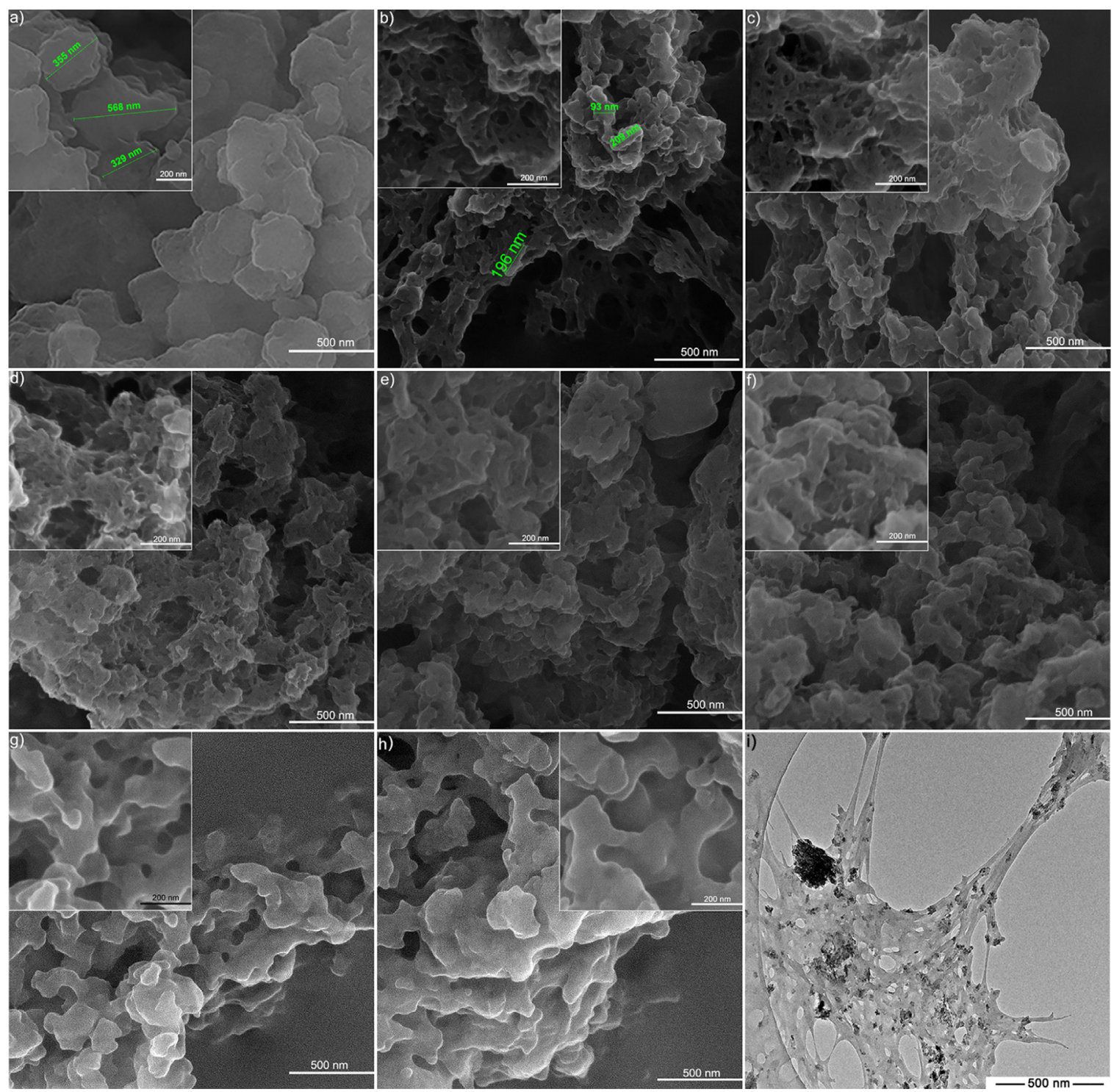

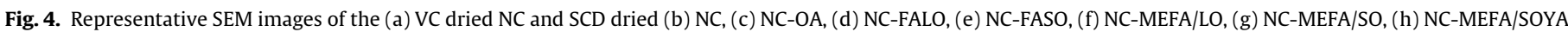
and (i) TEM micrograph of NC.

tion, and thus significantly reduced particle diameter $(400 \mathrm{~nm})$ was obtained. Robles, Urruzola, Labidi, and Serrano, (2015) confirmed that the NC modification with FA, due to introduction of aliphatic chains into whole region around the crystal particles, contributes to increased crystallite size for about 53\%, compared to unmodified NC sample. findings are observed for FA and MEFA modified NC, except for NC-FALO sample. De-agglomerated particles of NC-FASO and NC-MEFA/SOYA, with average diameters of 293 and $280 \mathrm{~nm}$, respectively, were found. The same trend is observed for deviation of particle size distribution. The $\mathrm{pH}$ dependence of the $\zeta$ potential was investigated, with the background of $0.01 \mathrm{M} \mathrm{HCl}$ acid solution; results are presented in Fig. S6. (Supporting information). All samples reach $\zeta \approx 0$ at $\mathrm{pH}$ values lower than 1.0.

\subsection{Reinforcement effect of $m$-NC in UPe based nanocomposites}

The NC surface modification was designed to provide change of surface properties from hydrophilic (NC) to mainly hydrophobic in $\mathrm{m}-\mathrm{NC}$. Concomitant introduction of vinyl functionalities, present in FA, either directly attached to NC surface or via cross linker, i.e. MA-EDA bridging group, as reactive centers is applicable for modification/reaction with different agent/polymer matrix. The significance of the vinyl group involved in cross linking reaction was recently unequivocally evidenced (Rusmirović et al., 2016). Except cross-linking reactivity during curing in UPe (Rusmirović et al., 2015; Rusmirović et al., 2016), vinyl containing FA residues provide better compatibility and physical reinforcing effect due to existence of different intermolecular interactions: dipolar, dispersive as well as hydrogen bonding interactions (Fig. S2).

Obtained nanomaterials were introduced in UPe in order to study relation between loading $\mathrm{m}$-NC versus mechanical properties of the obtained nanocomposites. The determination of mechanical properties, i.e. stress at break $\left(\sigma_{\mathrm{b}}\right)$, Young modulus $(E)$ and elongation at break $\left(\varepsilon_{\mathrm{b}}\right)$ of UPe/NC nanocomposites with $1 \mathrm{wt} \%$ nanofiller loading was performed. The results are presented in Table 4 while corresponding stress-strain curves are presented in Fig. S7 (Supporting information).

The obtained results indicate that high performances nanocomposites, based on UPe, was obtained by appropriate design of the nanofiller modification. The $\mathrm{m}-\mathrm{NC}$ reinforced composites exhibit higher mechanical properties than neat cured UPe matrix due to increased hydrophobicity of NC surface, i.e. improved compatibil- 
Table 4

Values of $\sigma_{\mathrm{b}}, \varepsilon_{\mathrm{b}}$ and $E$ of cured UPe/NC nanocomposites.

\begin{tabular}{|c|c|c|c|c|c|c|c|}
\hline Sample & $\sigma_{\mathrm{b}}[\mathrm{MPa}]$ & $\varepsilon_{\mathrm{b}} \quad[\%]$ & $E[\mathrm{GPa}]$ & Sample & $\sigma_{\mathrm{b}}[\mathrm{MPa}]$ & $\varepsilon_{\mathrm{b}} \quad[\%]$ & $E[\mathrm{GPa}]$ \\
\hline UPe & $43 \pm 0.9$ & $2.8 \pm 0.08$ & 1.8 & UPe/NC-FASO & $79 \pm 1.7$ & $4.5 \pm 0.08$ & 1.8 \\
\hline $\mathrm{UPe} / \mathrm{NC}$ & $59 \pm 1.2$ & $3.2 \pm 0.08$ & 1.9 & UPe/NC-MEFA/LO & $81 \pm 1.6$ & $4.5 \pm 0.07$ & 1.9 \\
\hline UPe/NC-FAOA & $76 \pm 1.9$ & $3.9 \pm 0.09$ & 2.0 & UPe/NC-MEFA/SO & $82 \pm 1.7$ & $4.5 \pm 0.09$ & 2.0 \\
\hline UPe/NC-FALO & $81 \pm 1.6$ & $5.4 \pm 0.10$ & 1.6 & UPe/NC-MEFA/SOYA & $83 \pm 1.8$ & $5.5 \pm 0.09$ & 1.5 \\
\hline
\end{tabular}

ity with UPe matrix, and vinyl reactivity sites contribute to higher cross-linking density. The stress at break of UPe/m-NC reflects the influence of vinyl modification on the NC dispersibility and extent of intermolecular interactions (Fig. S2) which contribute to effective networking of the obtained system and steric interference of FA residues.

Lower values of stress at break for FA modified NC is influenced by steric/conformational effects and availability of vinyl groups for cross-linking reactions. The higher values of stress at break, $\sigma_{\mathrm{b}}$, of UPe/m-NC with MEFA introduced via cross linker probably is due to the presence of the number of available ethylenic bonds in flexible structure which is more likely to be involved in cross-linking process. Besides, being attached directly at surface MA-EDA linker has more polar fragments compatible with UPe polymeric chain, thus providing better wetting of m-NC surface and forming interpenetrating network of fatty acid residues/UPe polymeric chains. Due to high hydrophobicity of FA directly attached to NC surface, it is more probable that FA residues occupy unfavorable twisted conformation on that way decreasing availability of ethylenic groups.

According to all results presented here, the aim of the future studies will be directed to complete/detail study on the influence of vinyl NC modification on the cross-linking kinetics, morphological, physico-mechanical and dynamic-mechanical analysis of obtained nanocomposites which will be devoted to better understanding of the interactions between functionalities and structures.

\section{Conclusion}

In this study, NC was prepared by acidic hydrolysis of the cellulose microfibrils using sulfuric acid. By sulfuric acid hydrolysis (acid concentration $64 \%$ ) during $40 \mathrm{~min}$ at the temperature of $40^{\circ} \mathrm{C}$, stable colloidal NC suspension was obtained (32\% yield of NC). In order to prevent self-association of NC and improve dispersibility in non-polar media, two modification methods, direct and via MA-EDA cross linker, were performed with FAs and MEFA isolated from linseed, sunflower and soya bean oils. Structural analysis confirmed successfulness of NC esterification. SCD post-treatment applied on modified NC induced transition from crystalline to amorphous form; and this method contributes to better dimensional and thermal stability. These properties in conjunction with the presence of vinyl reactive sites in FAs residues contribute to significant reinforcing effect of all $\mathrm{m}-\mathrm{NC}$ in produced UPe based nanocomposites. Thermal degradation of VC and SCD dried unmodified NC and all m-NC samples took place in three-step process. The transition temperature of dehydration (Region I) was shifted to the higher temperature for the MEFA modified NC compared to FA modified NC. Influences of bonding type of FAs on degradation profile were clearly observed in the course of Regions II and III: the effect on crystal structure decomposition of the FA modified NC was observed for both Regions (at $>155^{\circ} \mathrm{C}$ ), while the noticeable influence for MEFA modified CNS was observed in Region III, i.e. at $>300^{\circ} \mathrm{C}$. Applying of SCD method to NC preserved nanosized characteristics and homogenous particle size distribution, while the VC drying method resulted in the NC particles greater than $8 \mu \mathrm{m}$.

\section{Acknowledgements}

The authors acknowledge financial support from Ministry of Education, Science and Technological development of Serbia, Project No. OI 172057.

\section{Appendix A. Supplementary data}

Supplementary data associated with this article can be found, in the online version, at http://dx.doi.org/10.1016/j.carbpol.2017.01. 086.

\section{References}

Abdul Khalil, H. P. S., Davoudpour, Y., Islam, M. N., Mustapha, A., Sudesh, K., Dungani, R., \& Jawaid, M. (2014). Production and modification of nanofibrillated cellulose using various mechanical processes: A review. Carbohydrate Polymers, 99, 649-665. http://dx.doi.org/10.1016/j.carbpol.2013. 08.069

Agarwal, U. P., Reiner, R. S., Filpponen, I., Isogai, A., \& Argyropoulos, D. S. (2010). Crystallinities of nanocrystalline and nanofibrillated celluloses by FT-Raman spectroscopy. International Conference on Nanotechnology for the Forest Products Industry, 295-325. http://dx.doi.org/10.13140/2.1.4976.1280

Akur, V. K. T. (2015). Nanocellulose polymer nanocomposites. In V. K. T. Akur (Ed.),. Salem, Massachusetts: Scrivener Publishing LLC.

Almasi, H., Ghanbarzadeh, B., Dehghannia, J., Pirsa, S., \& Zandi, M. (2015). Heterogeneous modification of softwoods cellulose nanofibers with oleic acid: Effect of reaction time and oleic acid concentration. Fibers and Polymers, 16(8), 1715-1722. http://dx.doi.org/10.1007/s12221-015-4294-1

Almasi, H., Ghanbarzadeh, B., Dehghannya, J., Entezami, A. A., \& Khosrowshahi Asl, A. (2015). Novel nanocomposites based on fatty acid modified cellulose nanofibers/poly(lactic acid): Morphological and physical properties. Food Packaging and Shelf Life, 5, 21-31. http://dx.doi.org/10.1016/j.fpsl.2015.04.003

Beck, S., Bouchard, J., \& Berry, R. (2012). Dispersibility in water of dried nanocrystalline cellulose. Biomacromolecules, 13(5), 1486-1494. http://dx.doi. org/10.1021/bm300191k

Bellmann, C., Caspari, A., Albrecht, V., Doan, T. T. L., Mäder, E., Luxbacher, T., \& Kohl, R. (2005). Electrokinetic properties of natural fibres. Colloids and Surfaces A: Physicochemical and Engineering Aspects, 267(1-3), 19-23. http://dx.doi.org/10. 1016/j.colsurfa.2005.06.033

Chirayil, C. J., Joy, J., Mathew, L., Koetz, J., \& Thomas, S. (2014). Nanofibril reinforced unsaturated polyester nanocomposites: Morphology, mechanical and barrier properties, viscoelastic behavior and polymer chain confinement. Industrial Crops and Products, 56, 246-254. http://dx.doi.org/10.1016/j.indcrop.2014.03. 005

Dufresne, A. (2012). Nanocellulose: from nature to high performance tailored materials. Berlin: De Gruyter.

Eichhorn, S. J. (2011). Cellulose nanowhiskers: promising materials for advanced applications. Soft Matter, 7(2), 303. http://dx.doi.org/10.1039/c0sm00142b

Espert, A., Vilaplana, F., \& Karlsson, S. (2004). Comparison of water absorption in natural cellulosic fibres from wood and one-year crops in polypropylene composites and its influence on their mechanical properties. Composites Part A: Applied Science and Manufacturing, 35(11), 1267-1276. http://dx.doi.org/10. 1016/j.compositesa.2004.04.004

Eyholzer, C., Bordeanu, N., Lopez-Suevos, F., Rentsch, D., Zimmermann, T., \& Oksman, K. (2010). Preparation and characterization of water-redispersible nanofibrillated cellulose in powder form. Cellulose, 17(1), 19-30. http://dx.doi. org/10.1007/s10570-009-9372-3

Habibi, Y. (2014). Key advances in the chemical modification of nanocelluloses. Chemical Society Reviews, 43(5), 1519-1542. http://dx.doi.org/10.1039/ c3cs60204d

Heath, L., \& Thielemans, W. (2010). Cellulose nanowhisker aerogels. Green Chemistry, 12(8), 1448. http://dx.doi.org/10.1039/c0gc00035c

Hirata, T., \& Nishimoto, T. (1991). DSC, DTA, and TG of cellulose untreated and treated with flame-retardants. Thermochimica Acta, 193(C, 99-106. http://dx. doi.org/10.1016/0040-6031(91)80177-K

Hu, W., Chen, S., Xu, Q., \& Wang, H. (2011). Solvent-free acetylation of bacterial cellulose under moderate conditions. Carbohydrate Polymers, 83(4), 1575-1581. http://dx.doi.org/10.1016/j.carbpol.2010.10.016

Ibrahim, I. K., Hussin, S. M., \& Al-obaidi, Y. M. (2015). Extraction of cellulose nano crystalline from cotton by ultrasonic and its morphological and structural 
characterization. International Journal of Materials Chemistry and Physics, 1(2), 99-109.

Jecklin, M. C., Gamez, G., \& Zenobi, R. (2009). Fast polymer fingerprinting using flowing afterglow atmospheric pressure glow discharge mass spectrometry. The Analyst, 134(8), 1629. http://dx.doi.org/10.1039/b819560a

Joly, N., Granet, R., Branland, P., Verneuil, B., \& Krausz, P. (2005). New methods for acylation of pure and sawdust-extracted cellulose by fatty acid derivatives-Thermal and mechanical analyses of cellulose-based plastic films. Journal of Applied Polymer Science, 97(3), 1266-1278. http://dx.doi.org/10.1002/ app. 21783

Junior de Menezes, A., Siqueira, G., Curvelo, A. A. S., \& Dufresne, A. (2009). Extrusion and characterization of functionalized cellulose whiskers reinforced polyethylene nanocomposites. Polymer, 50(19), 4552-4563. http://dx.doi.org/ 10.1016/j.polymer.2009.07.038

Kalia, S., Kaith, B. S., \& Inderjeet, K. (2009). Pretreatments of natural fibers and their application as reinforcing material in polymer composites-A Review. Polymer Engineering and Science, 49, 1253-1272. http://dx.doi.org/10.1002/pen21328

Kargarzadeh, H., Sheltami, R., Ahmad, I., Abdullah, I., \& Dufresne, A. (2015). Cellulose nanocrystal: A promising toughening agent for unsaturated polyester nanocomposite. Polymer, 56, 346-357. http://dx.doi.org/10.1016/j.polymer. 2014.11.054

Kulomaa, T., Matikainen, J., Karhunen, P., Heikkilä, M., Fiskari, J., \& Kilpeläinen, I. (2015). Cellulose fatty acid esters as sustainable film materials - effect of side chain structure on barrier and mechanical properties. RSC Adv., 5(98), 80702-80708. http://dx.doi.org/10.1039/C5RA12671A

Lee, A. K. Y., Ling, T. Y., \& Chan, C. K. (2008). Understanding hygroscopic growth and phase transformation of aerosols using single particle Raman spectroscopy in an electrodynamic balance. Faraday Discussions, 137(852), 245-263. http://dx. doi.org/10.1039/B704580H

Liebner, F., Haimer, E., Wendland, M., Neouze, M. A., Schlufter, K., Miethe, P., \& Rosenau, T. (2010). Aerogels from unaltered bacterial cellulose: Application of $\mathrm{scCO}_{2}$ drying for the preparation of shaped, ultra-lightweight cellulosic aerogels. Macromolecular Bioscience, 10(4), 349-352. http://dx.doi.org/10.1002/ mabi.200900371

Peng, Y., Gardner, D. J., \& Han, Y. (2012). Drying cellulose nanofibrils: in search of a suitable method. Cellulose, 19(1), 91-102. http://dx.doi.org/10.1007/s10570011-9630-Z

Peng, Y., Gardner, D. J., Han, Y., Cai, Z., \& Tshabalala, M. A. (2013). Influence of drying method on the surface energy of cellulose nanofibrils determined by inverse gas chromatography. Journal of Colloid and Interface Science, 405 85-95. http://dx.doi.org/10.1016/j.jcis.2013.05.033

Peng, Y., Gardner, D. J., Han, Y., Kiziltas, A., Cai, Z., \& Tshabalala, M. A. (2013). Influence of drying method on the material properties of nanocellulose I: thermostability and crystallinity. Cellulose, 20(5), 2379-2392. http://dx.doi. org/10.1007/s10570-013-0019-Z

Peng, Y., Han, Y., \& Gardner, D. J. (2012). Spray-drying cellulose nanofibrils: Effect of drying process parameters on particle morphology. Wood and Fiber Science, 44(4), 1-14.

Postole, G., Bennici, S., \& Auroux, A. (2009). Calorimetric study of the reversibility of $\mathrm{CO}$ pollutant adsorption on high loaded Pt/carbon catalysts used in PEM fuel cells. Applied Catalysis B: Environmental, 92(3-4), 307-317. http://dx.doi.org/ 10.1016/j.apcatb.2009.08.009

Rančić, M., Rusmirović, J. D., Popović, I., \& Marinković, A. D. (2015). Isolation and chemical modification of nanocellulose nanocrystals for reinforcement of nanocomposites. Nanotechnol. Sci. Appl., 327-355.
Robles, E., Urruzola, I., Labidi, J., \& Serrano, L. (2015). Surface-modified nano-cellulose as reinforcement in poly(lactic acid) to conform new composites. Industrial Crops and Products, 71, 44-53. http://dx.doi.org/10.1016/ j.indcrop.2015.03.075

Rusmirović, J., Radoman, T., Džunuzović, E., Džunuzović, J., Markovski, J., Spasojević, P., \& Marinković, A. (2015). Effect of the modified silica nanofiller on the mechanical properties of unsaturated polyester resins based on recycled polyethylene terephthalate. Polymer Composites, http://dx.doi.org/10.1002/pc

Rusmirović, J., Trifković, K., Bugarski, B., Pavlović, V., Džunuzović, J., Tomić, M., \& Marinković, A. D. (2016). High performances unsaturated polyester based nanocomposites: Effect of vinyl modified nanosilica on mechanical properties. Express Polymer Letters, 10(2), 139-159. http://dx.doi.org/10.3144/ expresspolymlett.2016.14

Schenzel, K., Fischer, S., \& Brendler, E. (2005). New method for determining the degree of cellulose I crystallinity by means of FT Raman spectroscopy. Cellulose 12(3), 223-231. http://dx.doi.org/10.1007/s10570-004-3885-6

Sebestyén, Z., Jakab, E., May, Z., Sipos, B., \& Réczey, K. (2013). Thermal behavior of native, washed and steam exploded lignocellulosic biomass samples. Journal of Analytical and Applied Pyrolysis, 101, 61-71. http://dx.doi.org/10.1016/j.jaap. 2013.02.011

Socrates, G. (2004). Infrared and Raman characteristic group frequencies: Tables and Charts. John Wiley \& Sons.

Stojanović, D., Brajović, L., Orlović, A., Dramlić, D., Radmilović, V., Uskoković, P. S., \& Aleksić, R. (2013). Transparent PMMA/silica nanocomposites containing silica nanoparticles coating under supercritical conditions. Progress in Organic Coatings, 76(4), 626-631. http://dx.doi.org/10.1016/j.porgcoat.2012.12.002

Szymańska-Chargot, M., Cybulska, J., \& Zdunek, A. (2011). Sensing the structural differences in cellulose from apple and bacterial cell wall materials by raman and FT-IR spectroscopy. Sensors, 11(12), 5543-5560. http://dx.doi.org/10.3390 s110605543

Taleb, K., Markovski, J., Veličković, Z., Rusmirović, J., Rančić, M., Pavlovic, V., \& Marinković, A. (2016). Arsenic removal by magnetite-loaded amino modified nano/microcellulose adsorbents: Effect of functionalization and media size. Arabian Journal of Chemistry, http://dx.doi.org/10.1016/j.arabjc.2016.08.006 [Article in]

Tosh, B. (2011). Thermal analysis of cellulose esters prepared from different molecular weight fractions of high alpha-cellulose pulp. Indian Journal of Chemical Technology, 18(6), 451-457.

Uschanov, P., Johansson, L. S., Maunu, S. L., \& Laine, J. (2011). Heterogeneous modification of various celluloses with fatty acids. Cellulose, 18(2), 393-404. http://dx.doi.org/10.1007/s10570-010-9478-7

Wei, L., Stark, N. M., Sabo, R. C., \& Matuana, L. (2016). Modification of cellulose nanocrystals (CNCs) for use in poly(lactic acid)(PLA)-CNC composite packaging products. In Proceedings, Forest Products Society International Convention.

Wiley, J. H., \& Atalla, R. H. (1987). Band assigments in the Raman spectra of celluloses. Carbohydrate Research, 226.

Yoo, Y., \& Youngblood, J. P. (2016). Green one-pot synthesis of surface hydrophobized cellulose nanocrystals in aqueous medium. ASC Sustainable Chemistry, 4, 3927-3938. http://dx.doi.org/10.1021/acssuschemeng.6b00781

Zhang, K., Feldner, A., \& Fischer, S. (2011). FT Raman spectroscopic investigation of cellulose acetate. Cellulose, 18(4), 995-1003. http://dx.doi.org/10.1007/ s10570-011-9545-8

Zheng, Y., Lin, H. M., \& Tsao, G. T. (1998). Pretreatment for cellulose hydrolysis by carbon dioxide explosion. Biotechnology Progress, 14(6), 890-896. http://dx.doi org/10.1021/bp980087g 